Neural Control of Movement

\title{
Intra- and inter-rater reliability in the assessment and classification of the longitudinal plantar arch of children 6 to 10 years of age
}

\author{
Thiago Weyk de Oliveira Beliche ${ }^{1}$ (1) , Tânia Cristina Dias da Silva Hamu ${ }^{1,2}$ (D) , Rafaela Noleto dos Santos ${ }^{1}$ (1) , \\ Roberta Carneiro de Toledo ${ }^{1}$ (D) , Thailyne Bizinotto ${ }^{3}$ (D) , Celmo Celeno Porto ${ }^{3}$ (D) , Cibelle Kayenne Martins Roberto \\ Formiga $^{1,2}$ (1) \\ ${ }^{1}$ Universidade Estadual de Goiás, Programa de Pós-graduação em Ciências Aplicadas a Produtos para Saúde, Anápolis, GO, \\ Brasil; ${ }^{2}$ Universidade Estadual de Goiás, Departamento de Fisioterapia, Laboratório de Pesquisa em Musculoesquelética, \\ Goiânia, GO, Brasil,; ${ }^{3}$ Universidade Federal de Goiás, Programa de Pós-graduação em Ciências da Saúde, Goiânia, GO, Brasil \\ Associate Editor: Almir Vieira Dibai Filho. UFMA/São Luis, MA, Brasil.
}

\begin{abstract}
This study aimed to analyze the intra- and inter-rater reliability in the assessment and classification of the longitudinal plantar arch of children from 6 to 10 years old in the eyes-open (EO) testing condition. Methods: A total of two-hundred and seventy-eight Brazilian children (556 feet), boys and girls, from 6 to 10 years of age participated in the study. The children's feet were examined on a baropodometric platform, and the Staheli index was used for calculating the plantar arch index. Footprint analyses were performed at two different times, with an interval of 7 to 10 days, by three physical therapists in a single testing condition, resulting in 3,336 footprints. To determine the reliability of the continuous measurements, the Intraclass Correlation Coefficients (ICC) with $95 \%$ confidence intervals (CIs), Standard error of the mean (SEM), absolute value and percentage, and the Minimum Detectable Change (MDC) were calculated. To determine the reliability of the longitudinal arch classification, inter-rater reliability was evaluated by Weighted Fleiss Kappa Coefficient and the test-retest reliability was estimated by Weighted Cohen Kappa Coefficient. Results: Regarding inter-rater reliability, we observed values of ICC ranging from 0.79 to 0.96 ; thus, the results were classified as substantial to excellent reliability), being the lowest ICC values occur for line B, mainly in the first assessments. SEM ranges from 0.08 to 0.21 (percentage: 3.74 to 28.7), being the best, the lowest SEM values occur for Plantar Arch Index assessments and the MDC varies between 0.22 and 0.59 . Regarding intra-rater reliability, the results indicated excellent reliability: values of ICC range from 0.92 to 0.99 , being the lowest ICC values also occurs for line B analysis. SEM ranges from 0.03 to 0.20 (percentage: 2.32 to 26.6), being the lowest SEM values occur for Plantar Arch Index assessments and MDC varies between 0.09 and 0.54. Analyzing the interrater reliability for the longitudinal arch classifications, we observed values of Weighted Fleiss Kappa Coefficient ranging from 0.83 to 0.87 , expressing almost perfect agreement among the raters before and after evaluations. The testretest reliability of the longitudinal arch classification resulted in values of Weighted Cohen Kappa Coefficient ranging from 0.80 to 0.996 , expressing substantial to almost perfect agreement intra-rater. Conclusion: The study showed high reliability in the clinical assessment of the longitudinal plantar arch index of children from 6 to 10 years of age indicating that the Staheli method is applicable to pressure platform assessments with intra- and inter-rate reliability.
\end{abstract}

Keywords: assessments; child development; child health; data-accuracy

\section{Introduction}

The foot is essential for supporting body weight, and changes in its structure can cause musculoskeletal disorders, unstable postural control, and symptoms in children and adolescents ${ }^{1}$. During childhood, the development of the longitudinal arch of the foot occurs within the first six years of life, with variability in the structure and function of the feet; thus, it is very important to monitor this parameter in the clinical practice ${ }^{2}$.

The feet are anatomical structures that make it easier to perform important tasks (such as maintaining the orthostatic posture) and help in the strategies to maintain balance. In children, balance is an essential component influenced by motor development and skills that are important to movement ${ }^{3}$. There are three types of foot arches: normal or neutral foot, low or flat foot (pes planus), and high foot (pes cavus $)^{4}-$ the longitudinal arch is an essential component responsible for absorbing and dissipating forces in the feet ${ }^{5}$.

The plantar arch is modified as children grow. There is no longitudinal arch up to two years of age, and its natural growth accelerates until around five or six years of age. After early childhood, growth slows down and stability occurs at the age of 12 in girls, and around 13 or 14 in boys, depending on the child's motor experiences during the childhood ${ }^{6,7}$. Range of 
motion (ROM) and morphology are associated with foot function in children ${ }^{8}$ and can be measured through questionnaires ${ }^{9}$ and clinical assessments ${ }^{10,11}$.

In clinical practice, analysis instrumental can be used to assess and record the longitudinal plantar arch based on the morphological patterns of the feet, obtained through photopodoscopy and photopodometry ${ }^{11}$, radiographic measurements ${ }^{12}$, plantar ultrasound ${ }^{13}$, photogrammetry ${ }^{14}$, plantigraphy $^{15}$ and plantar pressure measurements obtained with a baropodometric platform ${ }^{16}$. Different indices, such as Cavanagh and Rodgers $\mathrm{AI}^{17}$, Staheli - $\mathrm{SI}^{18}$, Chippaux Smirak - CSI ${ }^{19}$, and Clarke's alpha angle $-\mathrm{AA}^{20}$, can be applied to assess the longitudinal plantar arch index and foot pattern prevalence. In a previous Brazilian study, the longitudinal arch of school-age children from 3 to 10 years old was characterized using four footprint classifications and calculated through the AI, SI, CSI, and AA indices ${ }^{21}$.

The Staheli method is widely used in Brazil because of its ease of application with children ${ }^{22}$, adolescents ${ }^{2,3}$, and adults ${ }^{24}$, including baropodometric measurements ${ }^{25}$, and has a high level of agreement with other indices ${ }^{26}$. Experimentally, knowledge about footprint measurement and its classification is necessary since professionals must base their interventions on reliable, evidence-based measurements. This study aimed to analyze intra- and inter-rater reliability in the assessment and classification of the longitudinal plantar arch of children from 6 to 10 years old in the eyes-open (EO) testing condition. The rationale is to add more information to the clinical practice of the foot assessments from school-age children.

\section{Material and Methods}

\section{Study design/sample characteristics}

This cross-sectional study was conducted in three full-time public schools in the city of Goiânia, Goiás, Brazil. A total of two-hundred seventy-eight children participated in the study (133 girls and 145 boys), between the ages of 6 and 10 years, with parental authorization, having signed the informed consent form. The exclusion criteria were children with musculoskeletal disorders, such as clubfoot, lower limb deficiencies, and leg length discrepancies that could affect measurements of the plantar arch index. No assessment method was employed for lower limb dysmetria. In this situation, the parents/guardians answered a questionnaire on the child's health condition; no complaint of discrepancies between members was presented regarding any of the children. The Ethics Committee for Research involving Human Subjects of the Federal University of Goiás approved the study under Protocol No. 71269717.0.0000.5083.

\section{Anthropometric measurements}

A G-Tech ${ }^{\circledR}$ digital scale, model Glass 10 , in tempered glass, with $100-\mathrm{kg}$ divisions and a maximum load of $150 \mathrm{~kg}$, and a portable stadiometer were used to collect the anthropometric measurements (weight, height, and body mass index). A baropodometric platform was used to obtain the anthropometric measurements of the feet (dimensions $565 \times 420 \times 25 \mathrm{~mm}$, active surface $490 \times 490 \mathrm{~mm}$, with capacitive sensors 4096 / $6 x 6$, frequency of $200 \mathrm{~Hz}$ and maximum pressure per sensor of $120 \mathrm{~N} / \mathrm{cm}^{2}$, Footwork Pro ${ }^{\circledR}$ software) (Figure 1$)^{16}$.

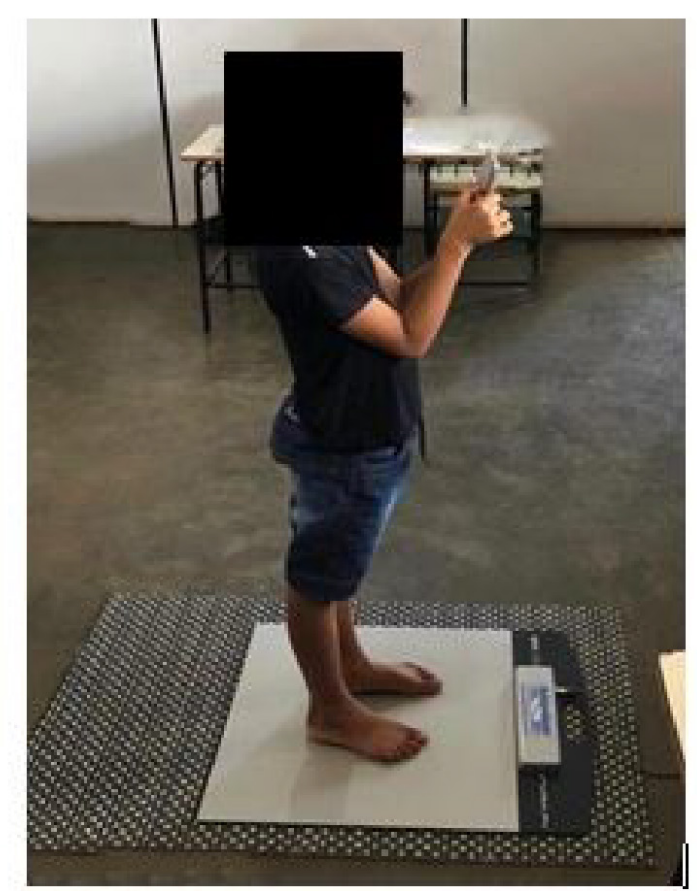

Figure 1 - Assessment with child on the plantar pressure platform.

\section{Procedures}

After measuring height and body mass, the children removed their shoes and socks and assumed an orthostatic position. The children were instructed to place one of their feet on the platform according to their preference and then the other. The assessments were performed under a single testing condition: Eyes open, where the children kept their upper limbs along the side of their body and aligned their eyes with a fixed point on the wall, at a distance of 1.5 meters (EO condition). For the test condition, the child remained 30 seconds on the platform (see Figure 1). The platform data were collected by two previously trained physical therapists and footprint analyses were performed by three physical therapy raters. The measurements were independently taken by the examiners.

After printing the plantar pressure images, the longitudinal arch index was calculated using the Staheli index, which establishes the ratio between the central and posterior region of the footprint. A line was drawn in reference to the longitudinal arch of the forefoot (Line A) and on the 
topography of the heel (Line B), and the plantar arch index was obtained by the division between the two lines. The children's feet were classified according to the values of the arch index: neutral $(0.3 \mathrm{~cm}$ and $1.0 \mathrm{~cm})$, flat $(>1.0 \mathrm{~cm})$, and high $(<0.3 \mathrm{~cm})^{18}$. In order to analyze data, the study had the participation of three physical therapists, who were experts in the field with clinical experience in foot arch assessment and were previously trained. For the analysis of the longitudinal arch of the foot, 556 feet were evaluated in a single testing condition. Each rater analyzed the footprints and repeated the analysis with new footprints after an interval of 7 to 10 days (test-retest). The total number of footprints analyzed in this study was 3,336 .

\section{Data Analysis}

For each foot measurement and the foot type classification, it was analyzed the reliability of the two assessment times, for each one of the three raters (intra-rater test-retest reliability), and the reliability of the measurement (or classification) inter the three raters (inter-rater reliability). To determine the reliability of the continuous measurements the Intraclass Correlation Coefficients (ICC) with 95\% confidence intervals (CIs) were calculated. The ICC estimates were calculated using a two-way mixed-effects model with absolute agreement. The level of reliability was established by the Fleiss classification ${ }^{27,28}$. According to Fleiss, the reliability by ICC values were considered low for ICC values below 0.40 ; moderate between 0.40 and 0.75 ; substantial between 0.75 and 0.90 ; and excellent greater than 0.90 . To assess measurement variability, the Standard Error of the Mean (SEM) also was calculated. This measurement is defined by with representing the total variance, and can be defined as an estimate of the expected random variation in scores when no real change has taken place and was calculated to provide an "absolute index of reliability" in the same units as the original measurement. The ICC is influenced by multiple sources of variation (eg, subjects, raters, trials) and by error, whereas the SEM is not influenced by variability among patients, is affected by error variation only ${ }^{29}$. The $95 \%$ confidence interval $(\mathrm{CI})$ to $\mathrm{SEM}$ was calculated as described by Brennan ${ }^{30}$. The following criteria were used for absolute measures: good if SEM $<10$ and poor if SEM $\geq 10$, according to Keogh et al. ${ }^{31}$ and McGinley et al. ${ }^{32}$. The SEM value was transformed into a percentage (SEM \%) for interpretation. The was defined as where is the mean for all observations. The values were interpreted as follows: $\leq 5 \%$, very good; $>5 \%$ and $\leq 10 \%$, good; $10 \%$ and $<20 \%$ $=$ doubtful; and $>20 \%=$ negative ${ }^{33}$. To determine any clinically important changes, the MDC (Minimum Detectable Change) was used and calculated using the equation. MDC can be defined as the minimal change that falls outside the measurement error in the result of an instrument used to measure a clinical characteristic ${ }^{34,35}$.

To determine the reliability of the foot type classification (ordinal variable) the Weighted Kappa Coefficient with linear weights and their respective $95 \%$ confidence intervals (CIs) were calculated. To assess intra-rater test-retest reliability (two classifications compared) was calculated the Weighted Cohen's Kappa Coefficient (WCKC). To assess inter-rater reliability (three classifications compared) was calculated the Weighted Fleiss' Kappa Coefficient (WFKC). The p-values significance test of ICC, WCKC, and WFKC were exhibited in the analysis. Landis and $\mathrm{Koch}^{36}$ provide a way to characterize Kappa values. According to their scheme, a Kappa value $<$ 0 is indicating no agreement, $0-0.20$ as slight, $0.21-0.40$ as fair, $0.41-0.60$ as moderate, $0.61-0.80$ as substantial, and $0.81-1$ as almost perfect agreement.

Statistical analysis was performed with a level of significance of 5\% using the Statistical Package for Social Sciences (SSPS version 23.0, IBM, Corp, Armonk, NY, USA), and Programming Software (R Core Team, 2020. R. Foundation for Statistical Computing, Vienna, Austria).

\section{Results}

The majority of the children were male $(52 \%, \mathrm{n}=133)$, and the mean age was $8.36 \pm 1.14$ years. The Body Mass Index was $17.3 \pm 3.34 \mathrm{~kg} / \mathrm{m}^{2}, \mathrm{CV}=0.19$ ). Tables 1 and 2 contain the inter-rater reliability results for before and after, respectively, the Line A and Line B measurements, and the plantar arch index test condition for both feet. Regarding inter-rate reliability, we observed values of ICC ranging from 0.79 to 0.96 , the results were classified as substantial to excellent reliability), being the lowest ICC values occurs for line B, mainly in the first assessments. The variability (SEM) ranges from 0.08 to 0.21 (percentage: 3.74 to 28.7), being the best, the lowest SEM values occur for Plantar Arch Index assessments and MDC varies between 0.22 and 0.59 .

Table 3 shows the intra-rater reliability obtained from the test condition and their respective measurements in the two assessments (test-retest). Regarding intra-rater reliability, we observed values of ICC ranging from 0.92 to 0.99 , being the lowest ICC values occur for line B analysis. The variability ranges from 0.03 to 0.20 (percentage: 2.32 to 26.6 ), being the lowest SEM values occur for Plantar Arch Index assessments and MDC varies between 0.09 and 0.54 . The results indicate excellent intra-rater reliability was obtained, which may be due to the measurement of the analyses in the 7- to 10-day intra-rater period.

Tables 4 and 5 present the frequencies to the foot type classifications by the Staheli method, before and after. Regarding inter-rater reliability for the classifications, we observed values of Weighted Fleiss Kappa Coefficient ranging from 0.83 to 0.87 , expressing almost perfect agreement among the raters in the before and after evaluations.

Table 6 provides the test-retest reliability results of the longitudinal arch classification. Regarding intra-rater reliability for the classifications, we observed values of Weighted Cohen Kappa Coefficient ranging from 0.80 to 0.996 , expressing substantial to almost perfect agreement intra -rater. 
Table 1 - Inter-rater reliability of the longitudinal arch index (first assessment)

\begin{tabular}{|c|c|c|c|c|c|c|c|c|c|c|c|c|}
\hline & \multirow{2}{*}{ Variables } & \multicolumn{2}{|c|}{ Rater 1} & \multicolumn{2}{|c|}{ Rater 2} & \multicolumn{2}{|c|}{ Rater 3} & \multirow[t]{2}{*}{$\operatorname{ICC}\left(\mathrm{CI}_{95 \%}\right)$} & \multirow[t]{2}{*}{$\mathbf{p}$} & \multirow[t]{2}{*}{$\operatorname{SEM}\left(\mathrm{CI}_{95 \%}\right)$} & \multirow[t]{2}{*}{ SEM\% $\left(\right.$ CI $\left._{95 \%}\right)$} & \multirow{2}{*}{$\begin{array}{c}\text { MDC } \\
\left(\mathrm{CI}_{95 \%}\right) \\
\end{array}$} \\
\hline & & Mean & SD & Mean & SD & Mean & SD & & & & & \\
\hline \multirow{4}{*}{$R$ foot } & \multicolumn{12}{|l|}{ Eyes open } \\
\hline & Line A & 0.85 & 0.86 & 0.84 & 0.89 & 0.87 & 0.89 & $0.94(0.93 ; 0.95)$ & $<0.001$ & $0.21(0.20 ; 0.33)$ & $24.8(23.4 ; 38.3)$ & $0.59(0.55 ; 0.91)$ \\
\hline & Line B & 2.39 & 0.29 & 2.42 & 0.30 & 2.45 & 0.29 & $0.85(0.82 ; 0.88)$ & $<0.001$ & $0.11(0.10 ; 0.17)$ & $4.58(4.12 ; 7.01)$ & $0.31(0.28 ; 0.48)$ \\
\hline & Plantar Arch Index & 0.35 & 0.35 & 0.34 & 0.36 & 0.35 & 0.36 & $0.94(0.93 ; 0.95)$ & $<0.001$ & $0.09(0.08 ; 0.14)$ & $25.3(22.9 ; 39.0)$ & $0.24(0.22 ; 0.38)$ \\
\hline \multirow{4}{*}{$L$ foot } & \multicolumn{12}{|l|}{ Eyes open } \\
\hline & Line A & 0.73 & 0.88 & 0.75 & 0.88 & 0.76 & 0.88 & $0.95(0.93 ; 0.96)$ & $<0.001$ & $0.20(0.19 ; 0.32)$ & $27.5(25.6 ; 42.5)$ & $0.57(0.53 ; 0.87)$ \\
\hline & Line B & 2.38 & 0.29 & 2.43 & 0.30 & 2.47 & 0.30 & $0.79(0.74 ; 0.83)$ & $<0.001$ & $0.13(0.12 ; 0.20)$ & $5.36(4.94 ; 8.27)$ & $0.36(0.33 ; 0.56)$ \\
\hline & Plantar Arch Index & 0.29 & 0.36 & 0.30 & 0.36 & 0.30 & 0.35 & $0.94(0.93 ; 0.95)$ & $<0.001$ & $0.09(0.08 ; 0.13)$ & $28.7(26.5 ; 44.3)$ & $0.24(0.22 ; 0.37)$ \\
\hline
\end{tabular}

R Foot: Right Foot; L Foot: Left Foot, SD: Standard Deviation, ICC: Intraclass Correlation Coefficient, $\mathrm{CI}_{95 \%}$ : Confidence Interval at $95 \%$ confidence level, SEM: Standard Error of Measurement; SEM\%: Standard Error of Measurement Percentual Relative to Global Mean; MDC: Minimal Detectable Chang

Table 2 - Inter-rater reliability of the longitudinal arch index (second assessment)

\begin{tabular}{|c|c|c|c|c|c|c|c|c|c|c|c|c|}
\hline & \multirow{2}{*}{ Variables } & \multicolumn{2}{|c|}{ Rater 1} & \multicolumn{2}{|c|}{ Rater 2} & \multicolumn{2}{|c|}{ Rater 3} & \multirow[t]{2}{*}{ ICC $\left(\mathrm{CI}_{95 \%}\right)$} & \multirow[t]{2}{*}{$\mathbf{p}$} & \multirow[t]{2}{*}{$\operatorname{SEM}\left(\mathrm{CI}_{95 \%}\right)$} & \multirow[t]{2}{*}{ SEM\% $\left(\mathrm{CI}_{95 \%}\right)$} & \multirow[t]{2}{*}{$\operatorname{MDC}\left(\mathrm{CI}_{95 \%}\right)$} \\
\hline & & Mean & SD & Mean & SD & Mean & SD & & & & & \\
\hline \multirow{4}{*}{$R$ foot } & Eyes open & & & & & & & & & & & \\
\hline & Line A & 0.85 & 0.86 & 0.84 & 0.89 & 0.88 & 0.89 & $0.95(0.94 ; 0.96)$ & $<0.001$ & $0.19(0.18 ; 0.20)$ & $22.4(21.0 ; 34.5)$ & $0.53(0.50 ; 0.82)$ \\
\hline & Line B & 2.40 & 0.30 & 2.43 & 0.30 & 2.46 & 0.29 & $0.91(0.89 ; 0.92)$ & $<0.001$ & $0.09(0.08 ; 0.14)$ & $3.74(3.29 ; 5.76)$ & $0.25(0.22 ; 0.39)$ \\
\hline & Plantar Arch Index & 0.35 & 0.35 & 0.34 & 0.36 & 0.35 & 0.35 & $0.95(0.94 ; 0.96)$ & $<0.001$ & $0.08(0.07 ; 0.13)$ & $23.4(20.0 ; 36.2)$ & $0.23(0.19 ; 0.35)$ \\
\hline \multirow{4}{*}{$L$ foot } & Eyes open & & & & & & & & & & & \\
\hline & Line A & 0.73 & 0.87 & 0.75 & 0.88 & 0.75 & 0.87 & $0.96(0.95 ; 0.97)$ & $<0.001$ & $0.18(0.17 ; 0.27)$ & $23.9(22.9 ; 36.8)$ & $0.49(0.47 ; 0.76)$ \\
\hline & Line B & 2.38 & 0.29 & 2.43 & 0.28 & 2.46 & 0.29 & $0.85(0.82 ; 0.88)$ & $<0.001$ & $0.11(0.10 ; 0.18)$ & $4.68(4.12 ; 7.22)$ & $0.31(0.28 ; 0.49)$ \\
\hline & Plantar Arch Index & 0.29 & 0.36 & 0.30 & 0.35 & 0.30 & 0.35 & $0.9590 .94 ; 0.96)$ & $<0.001$ & $0.08(0.07 ; 0.13)$ & $20.4(17.6 ; 31.4)$ & $0.22(0.19 ; 0.35)$ \\
\hline
\end{tabular}

Source: Author. Legend: R Foot: Right Foot; L Foot: Let Foot, SD: Standard Deviation, ICC: Intraclass Correlation Coefficient, CI95\%: Confidence Interval at 95\% confidence level, SEM: Standard Error of Measurement; SEM\%: Standard Error of Measurement Percentual Relative to Global Mean; MDC: Minimal Detectable Change.

Table 3 - Test-retest reliability of the longitudinal arch index (intra-rater)

\begin{tabular}{|c|c|c|c|c|c|c|c|c|c|}
\hline Rater & Foot & Variables & $\begin{array}{l}\text { Mean } \\
\text { Before }\end{array}$ & $\begin{array}{l}\text { Mean } \\
\text { After }\end{array}$ & $\begin{array}{c}\text { ICC } \\
\left(\mathrm{CI}_{95 \%}\right)\end{array}$ & $\mathbf{p}$ & $\operatorname{SEM}\left(\mathrm{CI}_{95 \%}\right)$ & SEM\% $\left(\mathrm{CI}_{95 \%}\right)$ & $\begin{array}{l}\text { MDC } \\
\left(\mathrm{CI}_{95 \%}\right)\end{array}$ \\
\hline & Right & Eyes open & & & & & & & \\
\hline & & Line A & 0.84 & 0.85 & $0.99(0.992 ; 1.00)$ & $<0.001$ & $0.07(0.06 ; 0.073)$ & $7.9(7.3 ; 8.6)$ & $0.19(0.17 ; 0.20)$ \\
\hline \multirow[t]{8}{*}{ Rater 1} & & Line B & 2.39 & 2.40 & $0.96(0.95 ; 0.97)$ & $<0.001$ & $0.06(0.056 ; 0.07)$ & $2.5(2.3 ; 2.8)$ & $0.17(0.16 ; 0.18)$ \\
\hline & & Plantar Arch Index & 0.35 & 0.35 & $0.99(0.98 ; 0.994)$ & $<0.001$ & $0.03(0.029 .0 .034)$ & $8.9(8.2 ; 9.7)$ & $0.09(0.08 ; 0.094)$ \\
\hline & Left & Eyes open & & & & & & & \\
\hline & & Line A & 0.73 & 0.73 & $0.98(0.97 ; 0.983)$ & $<0.001$ & $0.13(0.12 ; 0.14)$ & $17.7(16.3 ; 19.3)$ & $0.36(0.33 ; 0.39)$ \\
\hline & & Line B & 2.38 & 2.38 & $0.95(0.94 ; 0.96)$ & $<0.001$ & $0.06(0.05 ; 0.07)$ & $2.65(2.44 ; 2.89)$ & $0.17(0.16 ; 0.19)$ \\
\hline & & Plantar Arch Index & 0.29 & 0.30 & $0.98(0.97 ; 0.984)$ & $<0.001$ & $0.05(0.04 ; 0.06)$ & $17.0(15.7 ; 18.6)$ & $0.14(0.13 ; 0.15)$ \\
\hline & Right & Eyes open & & & & & & & \\
\hline & & Line A & 0.83 & 0.84 & $0.99(0.98 ; 0.992)$ & $<0.001$ & $0.09(0.08 ; 0.10)$ & $10.6(9.8 ; 11.2)$ & $0.25(0.23 ; 0.27)$ \\
\hline \multirow[t]{6}{*}{ Rater 2} & & Line B & 2.42 & 2.43 & $0.97(0.936 ; 0.97)$ & $<0.001$ & $0.06(0.05 ; 0.062)$ & $2.32(2.15 ; 2.54)$ & $0.16(0.14 .0 .17)$ \\
\hline & & Plantar Arch Index & 0.34 & 0.34 & $0.99(0.98 ; 0.992)$ & $<0.001$ & $0.04(0.03 ; 0.041)$ & $10.8(10.0 ; 11.8)$ & $0.10(0.09 ; 0.11)$ \\
\hline & Left & Eyes open & & & & & & & \\
\hline & & Line A & 0.75 & 0.73 & $0.95(0.94 ; 0.96)$ & $<0.001$ & $0.20(0.18 ; 0.21)$ & $26.6(24.6 ; 29.1)$ & $0.54(0.50 ; 0.59)$ \\
\hline & & Line B & 2.42 & 2.44 & $0.92(0.90 ; 0.94)$ & $<0.001$ & $0.08(0.077 ; 0.09)$ & $3.44(3.2 ; 3.8)$ & $0.23(0.21 ; 0.25)$ \\
\hline & & Plantar Arch Index & 0.30 & 0.30 & $0.99(0.989 ; 0.994)$ & $<0.001$ & $0.03(0.029 ; 0.035)$ & $10.7(9.8 ; 11.6)$ & $0.09(0.08 ; 0.10)$ \\
\hline
\end{tabular}




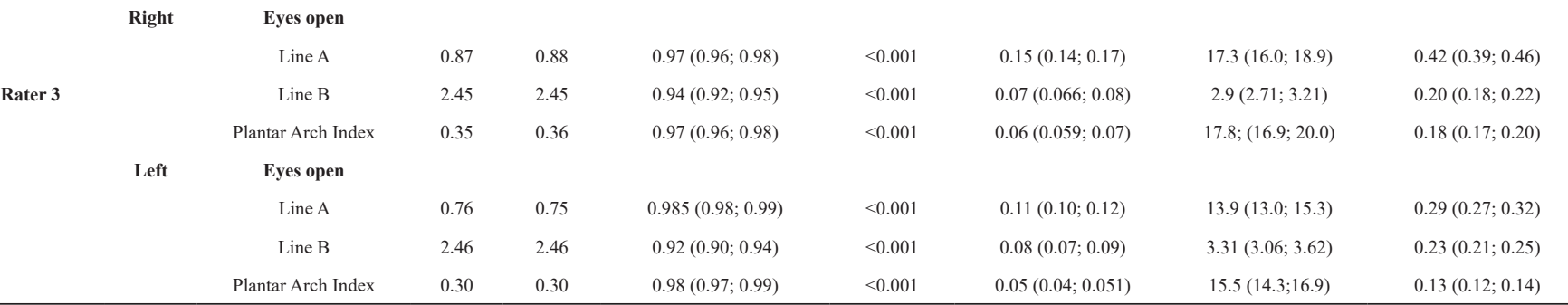

ICC: Intraclass Correlation Coefficient, $\mathrm{CI}_{95 \%}$ : Confidence Interval at 95\% confidence level, SEM: Standard Error of Measurement; SEM\%: Standard Error of Measurement Percentual Relative to Global Mean; MDC: Minimal Detectable Change.

Table 4 - Inter-rater reliability of the longitudinal arch classification (first assessment)

\begin{tabular}{|c|c|c|c|c|c|c|c|c|c|}
\hline \multirow{2}{*}{ Foot } & \multirow[b]{2}{*}{ Variables } & \multicolumn{2}{|c|}{ Rater 1} & \multicolumn{2}{|c|}{ Rater 2} & \multicolumn{2}{|c|}{ Rater 3} & \multirow[t]{2}{*}{ WFKC (CI (95\% $)$} & \multirow[t]{2}{*}{ p } \\
\hline & & $F(N)$ & F (\%) & $F(N)$ & F (\%) & $F(N)$ & F (\%) & & \\
\hline \multirow{4}{*}{ Right } & Eyes open (EC & & & & & & & \multirow{4}{*}{$0.83(0.80 ; 0.86)$} & \multirow{4}{*}{$<0.001$} \\
\hline & Neutral & 138 & 49.6 & 133 & 47.8 & 133 & 47.8 & & \\
\hline & Flat & 13 & 4.7 & 16 & 5.8 & 15 & 5.4 & & \\
\hline & High & 127 & 45.7 & 129 & 46.4 & 130 & 46.8 & & \\
\hline \multirow{4}{*}{ Left } & Eyes open (EC & & & & & & & \multirow{4}{*}{$0.85(0.82 ; 0.88)$} & \multirow{4}{*}{$<0.001$} \\
\hline & Neutral & 109 & 39.2 & 113 & 40.6 & 116 & 41.7 & & \\
\hline & Flat & 9 & 3.2 & 10 & 3.6 & 10 & 3.6 & & \\
\hline & High & 160 & 57.6 & 155 & 55.8 & 152 & 54.7 & & \\
\hline
\end{tabular}

Source: Author. Legend: L Foot: Left Foot; R: Right, WFKC: Weighted Fleiss Kappa Coefficient, p = p-value of Kappa’s significance.

Table 5 - Inter-rater reliability of the longitudinal arch classification (second assessment)

\begin{tabular}{|c|c|c|c|c|c|c|c|c|c|}
\hline \multirow{2}{*}{ Foot } & \multirow[b]{2}{*}{ Variables } & \multicolumn{2}{|c|}{ Rater 1} & \multicolumn{2}{|c|}{ Rater 2} & \multicolumn{2}{|c|}{ Rater 3} & \multirow[t]{2}{*}{ WFKC $\left(\mathrm{CI}_{95 \%}\right)$} & \multirow[t]{2}{*}{$\mathbf{p}$} \\
\hline & & $\mathbf{F}(\mathbf{n})$ & F (\%) & $\mathbf{F}(\mathbf{n})$ & F (\%) & $\mathbf{F}(\mathbf{n})$ & F (\%) & & \\
\hline \multirow{4}{*}{ Right } & Eyes open (EO & & & & & & & \multirow{4}{*}{$0.87(0.84 ; 0.89)$} & \multirow{4}{*}{$<0.001$} \\
\hline & Neutral & 140 & 50.4 & 131 & 47.1 & 139 & 50 & & \\
\hline & Flat & 11 & 4.00 & 14 & 5.01 & 13 & 4.7 & & \\
\hline & High & 127 & 45.7 & 133 & 47.8 & 126 & 45.3 & & \\
\hline \multirow{4}{*}{ Left } & Eyes open (EO & & & & & & & \multirow{4}{*}{$0.85(0.81 ; 0.87)$} & \multirow{4}{*}{$<0.001$} \\
\hline & Neutral & 112 & 40.3 & 119 & 42.8 & 114 & 41.0 & & \\
\hline & Flat & 9 & 3.2 & 9 & 3.2 & 11 & 4.0 & & \\
\hline & High & 157 & 56.5 & 150 & 54 & 153 & 55 & & \\
\hline
\end{tabular}

Source: Author. Legend: F(n): absolute frequency, F(\%): relative frequency. WFKC: Weighted Fleiss' Kappa Coefficient, $\mathrm{CI}_{95 \%}$ : Confidence Interval at $95 \%$ confidence level.

Table 6 - Test-retest reliability of the longitudinal arch classification (intra-rater)

\begin{tabular}{|c|c|c|c|c|c|c|c|c|c|c|c|c|c|}
\hline \multirow{2}{*}{ Foot } & \multirow[b]{2}{*}{ Variables } & \multicolumn{2}{|c|}{ Rater 1} & \multirow[t]{2}{*}{ WCKC $\left(\mathbf{C I}_{95 \%}\right)$} & \multirow[t]{2}{*}{$\mathbf{p}$} & \multicolumn{2}{|c|}{ Rater 2} & \multirow[t]{2}{*}{$\operatorname{WCKC}\left(\mathrm{CI}_{95 \%}\right)$} & \multirow[t]{2}{*}{$\mathbf{p}$} & \multicolumn{2}{|c|}{ Rater 3} & \multirow[t]{2}{*}{$\operatorname{WCKC}\left(\mathrm{CI}_{95 \%}\right)$} & \multirow[t]{2}{*}{$\mathbf{p}$} \\
\hline & & Before & After & & & Before & After & & & Before & After & & \\
\hline \multirow{5}{*}{ Right } & Eyes open & & & & & & & & & & & & \\
\hline & & & & & $<0.001$ & & & \multirow{4}{*}{$0.80(0.76 ; 0.84)$} & $<0.001$ & & & \multirow{4}{*}{$\begin{array}{c}0.90(0.88 \\
0.92)\end{array}$} & $<0.001$ \\
\hline & Neutral & 49.6 & 50.4 & 0.996 & & 47.8 & 47.1 & & & 47.8 & 50 & & \\
\hline & Flat & 4.7 & 4.0 & $(0.995 ; 0.997)$ & & 5.8 & 5.0 & & & 5.4 & 4.7 & & \\
\hline & High & 45.7 & 45.7 & & & 46.4 & 47.8 & & & 46.8 & 45.3 & & \\
\hline \multirow{4}{*}{ Left } & Eyes open & & & \multirow{4}{*}{$0.96(0.95 ; 0.97)$} & $<0.001$ & & & \multirow{4}{*}{$0.84(0.80 ; 0.87)$} & $<0.001$ & & & \multirow{4}{*}{$\begin{array}{c}0.95(0.94 \\
0.96)\end{array}$} & $<0.001$ \\
\hline & Neutral & 39.2 & 40.3 & & & 40.6 & 42.8 & & & 41.7 & 41.0 & & \\
\hline & Flat & 3.2 & 3.2 & & & 3.6 & 3.2 & & & 3.6 & 4.0 & & \\
\hline & High & 57.6 & 56.5 & & & 55.8 & 54 & & & 54.7 & 55 & & \\
\hline
\end{tabular}

Source: Author. Legend: Legend: F (\%): relative frequency. WCKC: Weighted Cohen’s Kappa Coefficient, $\mathrm{CI}_{95 \%}$ : Confidence Interval at $95 \%$ confidence level 


\section{Discussion}

This study assessed the intra-and inter-rater reliability of the longitudinal plantar arch measurement from children aged 6 to 10 years old. Reliability studies are very important in clinical practice and research because they provide more safety to the use of treatment and assessment techniques. Our findings indicate that the raters achieved high and very high levels of reliability in the children's footprint analyses, using baropodometry.

In clinical practice, professionals must be sure to use reliable and reproducible measurements. Therefore, studies need to demonstrate reliability in relation to measurements taken, and both reproducibility and repeatability must be tested, considering the quality of inter-and intra-reliability results, respectively ${ }^{11,37}$.

A previous study using the Staheli and Chippaux-Smirak indices revealed that measurements of the plantar arch index yielded excellent inter-rater and test-retest reliability in footprints of school-age children from 6 to 10 years old ${ }^{26}$. Another study investigated intra-day reliability (two different times of the day) and inter-rater reliability of the arch index results for eight-year-old children, assessed by a pressure platform under two different conditions: static and dynamic. The results revealed that, regardless of the test condition, the reliability of the measurements was high ${ }^{37}$. In the present study, the children were assessed in a single testing condition: eyes open (EO). It was verified that in such a testing condition, the repeatability and reproducibility of the arch index ranged from high to very high. The reason for that might be that the index used in the measurements was manually drawn up and calculated by the raters themselves. Even with an interval of 7 to 10 days between the assessments, the arch index remained reliable among the raters. Accordingly, a previous study comparing the data from three different plantar arch indices (Chippaux-Smirak, Staheli, and Clarke) assessed by a manual method and using Photoshop CS5 Software revealed good agreement among the techniques, indicating that the two have clinical applicability for assessing young people's footprints ${ }^{38}$.

In a study of 12-year-old children, there was high test-retest reliability among plantar arch index measurements using Clarke's angle and radiographic measurements. The study suggests that Clarke's angle is reliable and sensitive for quantifying medial arch height in children and is recommended for use in studies and clinical applications ${ }^{39}$. In another study, the Staheli and Chippaux-Smirak indices were used to compare the longitudinal plantar arch index of the feet of Brazilian and German children from 3 to 10 years of age, through a pedigraph (Foot Imprinter Harris Mat). There was no difference among the arch index values for all the age ranges assessed, except for four-year-old, children who had lower values on the Chippaux-Smirak index ${ }^{40}$. The application of the Cavanagh and Rodgers, Staheli, Chippaux-Smirak, and Clarke's angle indices resulted in good reliability based on the intraclass correlation coefficient ${ }^{41}$. In this study, the Staheli index proved to be valid and indicated good reliability through pressure platform analysis, as shown by the high ICC values, and can be recommended for studies and clinical applications.
The Staheli index is widely used in Brazil ${ }^{22}$ and other countries $^{42}$ for classifying foot types in different populations. In the present study, with footprints captured by a baropodometric platform, the Staheli index indicated a low prevalence of flat feet in the sample. This finding was consistent among the raters with high test-retest reliability. The prevalence of flat feet was similar in a study conducted with children in the same age range in Taiwan ${ }^{26}$.

Two systematic review studies found a prevalence of $4 \%$ to $15 \%$ of flat feet in school-age children ${ }^{43,44}$. In the activities of daily living in children, the feet positively influence the maintenance of postural stability. Normative data indicate that flat foot is a normal finding in children in their early years of life, which changes with their motor experiences as the children grow up and development ${ }^{7,45}$. In the present study, taking into consideration intra- and inter-rater reliability in the before and after comparison, the prevalence of flat feet ranged from $4 \%$ to $8.3 \%$, which confirms the findings of previous studies.

Baropodometric platforms are usually used to assess balance, postural control, and plantar pressure ${ }^{46}$. In the present study, the platform was used to generate footprint images. The findings revealed that this method yielded reliable and consistent measurements among the different rater, since there was a high correlation between their measurements during the analyses.Regardless of the test condition assessed, the results were consistent and reproducible. The values for the index and classification of the longitudinal arch of the foot did not change over time. Some limitations are pointed out, such as the lack of parameters to classify the plantar arch in the baropodometric platform used. Considering this limitation, and that there are no parameters in the literature for the collection method used, it is believed that the present findings will be useful as a reference for future studies. The use of reliable, evidence-based techniques can assist in the assessment, intervention, and prognosis of possible foot alterations.

\section{Conclusion}

Our findings confirm a good intra- and inter-rater reliability in the assessment and classification of the longitudinal plantar arch of children from 6 to 10 years old. The study could contribute to the clinical practice of both professionals and researchers who work with children's and adolescents' postural assessment and intervention methods.

\section{References}

1. Rao S, Riskowski JL, Hannan MT. Musculoskeletal conditions of the foot and ankle: Assessments and treatment options. Best Pract Res Clin Rheumatol. 2012;26(3):345-68. https://doi. org/10.1016/j.berh.2012.05.009

2. Buldt AK, Menz HB. Incorrectly fitted footwear, foot pain, and foot disorders: a systematic search and narrative review of the literature. J Foot Ankle Res. 2018;11:43. https://doi.org/10.1186/ s13047-018-0284-Z 
3. Tiberio D. Pathomechanics of structural foot deformities. Phys Ther. 1988; 68: 1840-49. PMID: 3194451

4. Hamill, Joseph; Knutzen, Kathleen M. Bases biomecânicas do movimento humano. 2. ed. Barueri: Manole, 2008. 494 pp.

5. Jahss MH. Disorders of the foot. WB Saunders Company: Philadelphia; 1982.

6. Tong JWK, Kong PW. Medial Longitudinal Arch Development of Children Aged 7 to 9 Years: Longitudinal Investigation. Phys Ther. 2016;96(8):1216-24. https://doi.org/10.2522/ptj.20150192

7. Uden H, Scharfbillig R, Causby R. The typically developing paediatric foot: how flat should it be? A systematic review. J Foot Ankle Res. 2017;10:37. https://doi.org/10.1186/s13047-017-0218-1

8. Alves C, Lysenko M, Tomlinson GA, Donovan J, Narayanan UG, Feldman BM, et al. plantar flexion, dorsiflexion, range of movement, and hindfoot deviation are important determinants of foot function in children. J Child Orthop. 2019;13(5):486-99. https:// doi.org/10.1302/1863-2548.13.190062

9. Morris C, Doll HA, Wainwright A, Theologis T, Fitzpatrick R. The Oxford ankle foot questionnaire for children. J Bone Joint Surg Am. J Bone Joint Surg [Br]. 2008;90-B:1451-6. https://doi. org/10.1302/0301-620X.90B11.21000

10. Mickle KJ, Steele JR, Munro BJ. The Feet of Overweight and Obese Young Children: Are They Flat or Fat? Obesity. 2006;14(11):194953. https://doi.org/10.1038/oby.2006.227

11. Ribeiro AP, Trombini-Souza F, Iunes DH, Monte-Raso VV. Confiabilidade inter e intra-examinador da fotopodometria e intra-examinador da fotopodoscopia. Rev Bras Fisioter. 2006; 10(4):435-39. https://doi.org/10.1590/S1413-35552006000400012

12. Chang JH, Wang SH, Kuo CL, Shen HC, Hong YW, Lin LC. Prevalence of flexible flatfoot in Taiwanese school-aged children in relation to obesity, gender, and age. Eur J Pediatr. 2010;169(4):44752. https://doi.org/10.1007/s00431-009-1050-9

13. Nakayama Y, Tashiro Y, Suzuki Y, Kajiwara Y, Zeidan H, Kawagoe $\mathrm{M}$, et al. Relationship between transverse arch height and foot muscles evaluated by ultrasound imaging device. J Phys Ther Sci. 2018;30(4):630-35. https://doi.org/10.1589/jpts.30.630

14. Iunes DH, Castro FA, Salgado HS, Moura IC, Oliveira AS, Bevilaqua-Grossi D. Confiabilidade inter e intra-examinadores e repetibilidade da avaliação postural pela fotogrametria. Rev Bras de Fisioterapia. 2005;9(3):249-55.

15. Bookstein FL, Domjanic J. The Principal Components of Adult Female Insole Shape Align Closely with Two of Its Classic Indicators. PLoS One. 2015;10(8):e0133303. https://doi. org/10.1371/journal.pone. 0133303

16. Demirbüken I, Özgül B, Timurtas E, Yurdalan SU, Çekin MD, Polat MG. Gender and age impact on plantar pressure distribution in early adolescence. Acta Orthop Traumatol Turc. 201;53(3):215220. https://doi.org/10.1016/j.aott.2019.01.006

17. Cavanagh PR, Rodgers MM. The arch index: a useful measure from footprints. J Biomech. 1987;20(5):547-51. https://doi. org/10.1016/0021-9290(87)90255-7

18. Staheli LT, Chew DE, Corbett M. The longitudinal arch. A survey of eight hundred and eighty-two feet in normal children and adults. J Bone Joint Surg. 1987; 69:426-8.

19. Forriol F, Pascual J. Footprint analysis between three and seventeen years of age. J Biomech. 1987;20(5):547-51. https://doi. org/10.1177/107110079001100208
20. Clarke HH. An Objective Method of Measuring the Height of the Longitudinal Arch in Foot Examinations. Res. Q. 1933;4(3):99107. DOI: $10.1080 / 23267402.1933 .10626636$

21. Onodera AN, Sacco ICN, Morioka EH, Souza PS, Sá MR, Amadio AC. What is the best method for child longitudinal plantar arch assessment and when does arch maturation occur? Foot (Edinb). 2008;18(3):142-9. https://doi.org/10.1016/j.foot.2008.03.003

22. Hernandez AJ, Kimura LK, Laraya MHF, Fávaro E. Cálculo do índice do arco plantar de Staheli e a prevalência de pés planos: estudo em 100 crianças entre 5 e 9 anos de idade. Acta Ortop Bras. 2007;15(2):68-71. http://dx.doi.org/10.1590/ S1413-78522007000200001

23. Filoni E, Martins Filho J, Fukuchi RK, Gondo RM. Comparison between different plantar arch. Motriz: J. Phys. Ed. 2009;15(4):85060. https://www.periodicos.rc.biblioteca.unesp.br/index.php/ motriz/article/view/1887

24. Pita-Fernández S, González-Martín C, Seoane-Pillado T, LópezCalviño B, Pértega-Díaz S, Gil-Guillén V. Validity of Footprint Analysis to Determine Flatfoot Using Clinical Diagnosis as the Gold Standard in a Random Sample Aged 40 Years and Older. J Epidemiol. 2015;25(2):148-54. https://doi.org/10.2188/jea. JE20140082

25. Baumfeld D, Baumfeld T, da Rocha RL, Macedo B, Raduan F, Zambelli R, et al. Reliability of Baropodometry on the Evaluation of Plantar Load Distribution: A Transversal Study. Biomed Res Int. 2017;2017:5925137. https://doi.org/10.1155/2017/5925137

26. Chang $\mathrm{CH}$, Chen YC, Yang WT, Ho PC, Hwang AW, Chen $\mathrm{CH}$, et al. Flatfoot Diagnosis by a Unique Bimodal Distribution of Footprint Index in Children. PLoS One. 2014;9(12): e115808. https://doi.org/10.1371/journal.pone.0115808

27. Fleiss JL. The Design and Analysis of Clinical Experiments. New York: John Wiley \& Sons; 1986.

28. Fleiss JL. The Design and Analysis of Clinical Experiments. Hoboken: John Wiley \& Sons, Inc., 1999.

29. Statford PW. Goldsmith CH. Use of the Standard Error as a Reliability Index of Interest: An Applied Example Using Elbow Flexor Strength Data. Physical Therapy. 1997; 77(7):745-50.

30. Brennan JL. Generalizability theory. New York: Springer; 2001.

31. Keogh JWL, Cox A, Anderson S, Liew B, Olsen A, Schram B, Furness J. Reliability and Validity of clinically accessible smartphone applications to measure joint range of motion. A systematic review. PloS ONE. 2019;14: e0215806.

32. MacGinley JL, Baker R, Wolfe R, Morris MF. The reliability of three-dimensional kinematic gait measurements: a systematic review. Gait Posture. 2009; 29:360-9.

33. Silva AC. Aily JB, Oliveira AB, Mattiello SM. Interrater and Intrarater Reliability and Minimum Detectable Change of Ultrasound for Active Myofascial Trigger Points in Upper Trapezius Muscle in Individuals With Shoulder Pain. J Manipulative Physiol Ther. 2020;43(9): 855-63. DOI:https:// doi.org/10.1016/j.jmpt.2020.01.003

34. Furlan L, Sterr A. The Applicability of Standard Error of Measurement and Minimal Detectable Change to Motor Learning Research-A Behavioral Study. Front Hum Neurosci. Frontiers Media SA. 2018; 12:95.

35. Kovacs FM. Abraira V, Royuela A, Corcoll J, Alegre L, Tomás $\mathrm{M}$, et al. Minimum detectable and minimal clinically important 
changes for pain in patients with nonspecific neck pain. BMC Musculoskelet. Disord. 2008; 9: 43.

36. Landis, J.R., Koch, G.G. The measurement of observer agreement for categorical data. Biometrics. 1977; 33(1): 159-74

37. Scholz T, Zech A, Wegscheider K, Lezius S, Braumann K-M, Sehner S, et al. Reliability and Correlation of Static and Dynamic Foot Arch Measurement in a Healthy Pediatric Population. J Am Podiatr Med Assoc. 2017;107(5):419-27. https://doi. org/10.7547/16-133

38. Gutiérrez-Vilahú L, Massó-Ortigosa N, Costa-Tutusaus L, Guerra-Balic M. Reliability and Validity of the Footprint Assessment Method Using Photoshop CS5 Software. J Am Podiatr Med Assoc. 2015;105(3):226-32. https://doi. org/10.7547/0003-0538-105.3.226

39. Pauk J, Ihnatouski M, Najafi B. Assessing Plantar Pressure Distribution in Children with Flatfoot Arch. J Am Podiatr Med Assoc. 2014;104(6):622-32. https://doi. org/10.7547/8750-7315-104.6.622

40. Sacco ICN, Onodera AN, Bosch K, Rosenbaum D. Comparisons of foot anthropometry and plantar arch indices between German and Brazilian children. BMC Pediatr. 2015;12,15:4. https://doi. org/10.1186/s12887-015-0321-Z

41. Zuil-Escobar JC, Martínez-Cepa CB, Martín-Urrialde JA, GómezConesa A. Medial Longitudinal Arch: Accuracy, Reliability, and Correlation Between Navicular Drop Test and Footprint Parameters. J Manipulative Physiol Ther. 2018;41(8):672-9. https://doi.org/10.1016/j.jmpt.2018.04.001

42. Punniakotti M, Purushothaman S, Sharma V. Correlation of Staheli's foot index and central distance measurement for classifying normal and flat-arched foot posture. Drug Invention Today. 2019;12(3):416-8.

43. Dare DM, Dodwell ER. Pediatric flatfoot: Cause, epidemiology, assessment, and treatment. Current Opinion in Pediatrics. 2014;26(1): 93-100. doi: 10.1097/MOP.0000000000000039

44. Carr JB, Yang S, Lather LA. Pediatric Pes Planus: A State-ofthe-Art Review. Pediatrics. 2016;137(3): e20151230. https://doi. org/10.1542/peds.2015-1230
45. Banwell H A, Paris M E, Mackintosh S, Williams, C M. Paediatric flexible flat foot: how are we measuring it and are we getting it right? A systematic review. J. Foot Ankle Res. 2018;11:21. doi:10.1186/s13047-018-0264-3

46. Yalçin N, Esen E, Kanatli U, Yetkin H. Evaluation of the medial longitudinal arch: a comparison between the dynamic plantar pressure measurement system and radiographic analysis. Acta Orthop Traumatol Turc. 2010;44(3):241-5. doi:10.3944/AOTT.2010.2233

\section{Acknowledgements}

This study was supported by the Fundação de Amparo a Pesquisa do Estado de Goiás (FAPEG) to FORMIGA, C.K.M.R. (Process 201810267000108) and scholarship to BELICHE, T. W. O. (Process 201810267000575) and BIZINOTTO, T. (Process 88887.162706/1028-00 FAPEG/CAPES).

\section{Corresponding author}

Thiago Weyk de Oliveira Beliche. State University of Goiás. BR 153 Quadra Área, Km 99. 75132-903. Anápolis, Goiás, Brasil. Telephone: + 55 (94) 98152-0020 Email: thiagofisio30@gmail.com

Manuscript received on July 31, 2020

Manuscript accepted on November 10, 2020

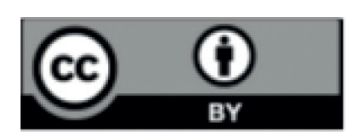

Motriz. The Journal of Physical Education. UNESP. Rio Claro, SP, Brazil - eISSN: 1980-6574 - under a license Creative Commons - Version 4.0 